\title{
Methods to prevent development of adductor muscle contraction during transurethral resection of lateral bladder wall tumors
}

\author{
Recai Dagli ${ }^{1}$, Mumtaz Dadali
}

\author{
${ }^{1}$ Department of Anaesthesiology and Reanimation, Faculty of Medicine, Ahi Evran \\ University, Kirsehir, Turkey \\ ${ }^{2}$ Department of Urology, Faculty of Medicine, Ahi Evran University, Kirsehir, Turkey
}

Submitted: 24 April 2018

Accepted: 25 June 2018

Arch Med Sci Civil Dis 2018; 3: e64-e69

DOI: https://doi.org/10.5114/amscd.2018.77011

Copyright @ 2018 Termedia \& Bnaach

\begin{abstract}
Introduction: Adductor muscle contraction may develop due to an electrical stimulus during transurethral resection of bladder tumors (TURBT), and thus bladder wall perforation and vessel-nerve injuries may develop. Studies in the literature demonstrated that obturator nerve block (ONB) was performed with high success and low complication rates to prevent adductor muscle contraction by both urologists and anesthesiologists. However, we found no data suggesting how frequently ONB was used in current practice in urology clinics. We aimed to provide data about ONB and other methods used in current practice to prevent adductor spasm developing during TURBT surgery in urology clinics.
\end{abstract}

Material and methods: A 15-item questionnaire investigating the methods and ONB techniques used against adductor spasm during TURBT surgery was posted by email to urologists after being granted ethics board approval. Results: One hundred seventy urologists completed and returned the forms. Urologists frequently used techniques such as lowering the cautery current (77.6\%), immediate stepping on, and stepping off the foot switch (45.8\%), decreasing the bladder volume (14.1\%), and wall injections $(4.7 \%)$. The ONB was used by 42 (24.7\%) urologists and 22 anesthesiologists (12.9\%); general anesthesia was preferred more often. No significant difference was detected in the comparison of the ONB methods or the institutions of the urologists $(p=0.51)$ and anesthesiologists $(p=0.07)$.

Conclusions: Urologists used different practices in accordance with their personal skills in the prevention of adductor muscle contraction in TURBT procedures. The ONB was preferred less and used less than general anesthesia and muscle relaxants by both urologists and anesthesiologists.

Key words: transurethral resection of bladder tumor, adductor spasm, obturator nerve block, bladder perforation, bipolar cautery, bladder wall injection.

\section{Introduction}

Adductor muscle contraction may develop due to electrical stimulus during transurethral resection of bladder tumor (TURBT) surgery, which is performed for the staging and treatment of lateral bladder wall tumors. Excessive contraction of the adductor longus, brevis, and magnus muscles, which are innervated by the obturator nerve, during TURBT may

\author{
Corresponding author: \\ Recai Dagli \\ Department of \\ Anaesthesiology \\ and Reanimation \\ Faculty of Medicine \\ Ahi Evran University \\ 4010 Kirsehir, Turkey \\ Fax: +90 5426536975 \\ E-mail: drresel@gmail.com
}


cause complications such as bladder perforation and vessel-nerve damage, resulting in increased recurrence due to inadequate resection $[1,2]$.

Various different methods have been tried for the prevention of adductor muscle spasm in TURBT surgery under regional anesthesia [3]. With this aim, urologists and anesthesiologists have performed obturator nerve block (ONB) using different methods. In addition, urologists use different approaches such as bipolar cautery practices, bladder wall injections, and changes of the fluid of transurethral resection (TUR) [4-6].

The obturator nerve stems from the lumbar plexus L2-L4. ONB may be performed in different areas during the navigation of the nerve [7]. Anesthesiologists prevent contractions of all muscles using muscle blocks under general anesthesia, or prevent the contraction of adductor muscles by performing ONB. Anesthesiologists mainly use the pubic or inguinal approach for ONB [8]. Blinding block may be performed in accordance with the anatomic points; however, possible vessel and nerve traumas and local anesthetic toxicity must be borne in mind. Anesthesiologists currently perform ONB under ultrasonography with a nerve stimulator due to these complications [9].

In many studies in the current literature, researchers found that ONB was performed with high success and with low complication rates by both urologists and anesthesiologists for the prevention of adductor muscle contraction, regardless of the method used [10-12]. However, we found no data regarding how frequently ONB was used in urology clinics in current practice.

We aimed to provide data about ONB and other methods used by urologists and anesthesiologists for the prevention of adductor spasm during TURBT surgery in current practice in urology clinics.

\section{Material and methods}

After obtaining approval from the Ethics Board of Clinical Studies in Ahi Evran (Date: 23.05.2017, Decision No: 2017-09/89), questionnaire forms were sent by email to urologists and we waited one month for their responses.

The questionnaire questioned the institutions of the urologists, their working duration as a specialist, the techniques performed for the prevention of adductor muscle contraction during TURBT surgery, and the devices and medications used. In addition, the urologists were asked about the methods, devices, and drugs used by anesthesiologists against adductor muscle spasm in the questionnaire. A 5-point Likert scale was used for the evaluation of the opinions of the urologists regarding ONB.

The SPSS (Statistical Package for Social Sciences, SPSS Inc., Chicago, IL, United States) 11.5
Windows program package was used in the data analysis. The $\chi^{2}$ test was used in the comparison of the qualitative data in addition to descriptive statistical methods (frequency, percentage, mean, standard deviation, median, and min.-max.) in the evaluation of the study data. The Kolmogorov-Smirnov and Shapiro-Wilk tests were used in the evaluation of the compatibility of the data to a normal distribution. The one-way analysis of variance (ANOVA) test was used in the between groups comparison. A $p$-value of $<0.05$ was regarded as significant.

Power analysis was performed using the statistical program $G^{*}$ Power 3.1.9.2. The power $(1-\beta)$ was found to be 0.92, $n=170, \alpha=0.05$, and the effect size $w=0.3, \mathrm{~d} f=3$.

\section{Results}

The demographic data of the 170 urologists who answered the questionnaire forms are presented in Table I.

In accordance with the responses, the urologists performed a mean of $33.4 \pm 36.0$ TURBT and observed $7.8 \pm 12.8$ adductor spasms in the last year. The observation rate of adductor spasms during TURBT was found to be $23.3 \%$.

The techniques and the ONB methods used by urologists for the prevention of adductor muscle contraction are presented in Table II.

The method used most frequently by the urologists in the prevention of adductor muscle contraction during TURBT surgery was using a low cautery current, which was used alone or together with other techniques $(77.6 \%, n=132)$. This method was often performed with the rapid step on-step off maneuver of the footswitch (45.8\%, $n=78)$. In addition to the other methods, another technique was decreasing the bladder volume $(14.1 \%, n=24)$. Eight $(4.7 \%)$ urologists administered local anesthesia in the bladder wall alone or in addition to ONB. No statistical-

Table I. Demographic data

\begin{tabular}{|lc|}
\hline Period as a urologist [years] & $\%(n)$ \\
\hline$<5$ & $28.2(48)$ \\
\hline $6-15$ & $43.5(74)$ \\
\hline $16-25$ & $12.9(22)$ \\
\hline$\geq 26$ & $15.3(26)$ \\
\hline Work place & $\%(n)$ \\
\hline Public hospital & $27.1(46)$ \\
\hline Education and training hospital & $20.0(34)$ \\
\hline Private hospital & $28.2(48)$ \\
\hline University hospital & $24.7(42)$ \\
\hline
\end{tabular}


Table II. Techniques and obturator nerve block methods used by the urologists

\begin{tabular}{|c|c|c|c|c|c|c|}
\hline Variable & $\begin{array}{c}\text { Public } \\
\text { hospital } \\
n(\%)\end{array}$ & $\begin{array}{l}\text { Education } \\
\text { and training } \\
\text { hospital } \\
n(\%)\end{array}$ & $\begin{array}{l}\text { Private } \\
\text { hospital } \\
n(\%)\end{array}$ & $\begin{array}{c}\text { University } \\
\text { hospital } \\
n(\%)\end{array}$ & $\begin{array}{l}\text { Total } \\
n(\%)\end{array}$ & $P$-value \\
\hline Classic ONB method & $8(17.4)$ & $6(17.6)$ & $7(14.6)$ & $13(31.0)$ & $34(20.0)$ & $0.511^{\star}$ \\
\hline Inguinal ONB method & - & $2(5.9)$ & $3(6.3)$ & $1(2.4)$ & $6(3.5)$ & \\
\hline Interfascial ONB method & $2(4.3)$ & - & - & - & $2(1.2)$ & \\
\hline Other ${ }^{\star *}$ & $36(78.3)$ & $26(76.5)$ & $38(79.2)$ & $28(66.7)$ & $128(75.3)$ & \\
\hline Total & $46(27.1)$ & $34(20.0)$ & $48(28.2)$ & $42(24.7)$ & $170(100.0)$ & \\
\hline
\end{tabular}

${ }^{\star}$ The comparison was performed with a combination (Classic ONB + inguinal ONB + interfascial ONB). ${ }^{* *}$ Lowering the cautery current, immediate step on-step off the footswitch, decreasing the bladder volume, local injection on the bladder wall.

ly significant difference was detected regarding the institutions, their practices, or ONB methods of the urologists $(p>0.05)$. The comparison of ONB methods was performed with a combination of the classic ONB, inguinal ONB, and interfascial ONB. The methods such as lowering the cautery current, immediate step on-step off of the footswitch, decreasing the bladder volume, and local injection in the bladder wall were combined, and the comparisons were conducted with the formation of an 'other' group.

Of the 42 urologists who performed ONB (24.7\%), 32 (18.9\%) used the blinding method, and 10 (5.9\%) used a peripheral nerve stimulator and/or ultrasonography. Urologists were found to use bipolar cautery $(58.8 \%, n=100)$ and monopolar cautery $(37.6 \%, n=64)$ in TURBT surgery. The urologists used isotonic saline $(57.7 \%, n=98)$, mannitol (32.9\%), and glycine (8.25\%), respectively, as the irrigation fluid.

Urologists used bupivacaine hydrochloride ( $n=$ 14) $10-15 \mathrm{ml}$ in a $0.25-0.5 \%$ concentration with a ratio of $1 / 1$ diluted with $0.09 \% \mathrm{NaCl}$, prilocaine hydrochloride $(n=12) 5-15 \mathrm{ml}$ in a concentration of $1-2 \%$, and lidocaine hydrochloride $(n=4) 10-$ $20 \mathrm{ml}$ in a concentration of $2-0.5 \%$, respectively, or a mixture of these drugs to perform ONB.

The question, "Which of the methods do anesthesiologists use for prevention of adductor spasm in TURBT?" was asked. The participant urologists responded that anesthesiologists did nothing (49.4\%), or anesthesiologists used general anesthesia and muscle relaxants (37.6\%), and ONB (12.9\%), respectively. The preferred ONB methods of the anesthesiologists are presented in Table III. Of the 22 anesthesiologists who performed ONB, 10 used the blinding method and 12 used a peripheral nerve stimulator and/or ultrasonography for blocking. Urologists reported that anesthesiologists frequently used bupivacaine hydrochloride, prilocaine hydrochloride, and lidocaine hydrochloride for ONB. No statistically significant difference was detected regarding the working institution and the methods of the anesthesiologists ( $p=0.07$ ).

The question, "Which method would you use as the first option against adductor spasm during TURBT?" was directed to the urologists, and their responses were general anesthesia and muscle

Table III. Techniques and obturator nerve block methods used by the anesthesiologists

\begin{tabular}{|c|c|c|c|c|c|c|}
\hline Variable & $\begin{array}{c}\text { Public } \\
\text { hospital } \\
n(\%)\end{array}$ & $\begin{array}{l}\text { Education } \\
\text { and training } \\
\text { hospital } \\
n(\%)\end{array}$ & $\begin{array}{c}\text { Private } \\
\text { hospital } \\
n(\%)\end{array}$ & $\begin{array}{c}\text { University } \\
\text { hospital } \\
n(\%)\end{array}$ & $\begin{array}{l}\text { Total } \\
n(\%)\end{array}$ & $P$-value \\
\hline Do not perform & $24(52.2)$ & $12(35.3)$ & $24(50.0)$ & $24(57.1)$ & $84(49.4)$ & $0.077^{*}$ \\
\hline $\begin{array}{l}\text { General anesthesia + } \\
\text { muscle relaxant }\end{array}$ & $18(39.1)$ & $12(35.3)$ & $20(41.7)$ & $14(35.3)$ & $64(37.6)$ & \\
\hline $\begin{array}{l}\text { Classic ONB method } \\
(n=14)\end{array}$ & $2(4.3)$ & $8(23.5)$ & - & $4(9.5)$ & $14(8.2)$ & \\
\hline $\begin{array}{l}\text { Inguinal ONB method } \\
(n=6)\end{array}$ & $2(4.3)$ & - & $4(8.3)$ & - & $6(3.5)$ & \\
\hline $\begin{array}{l}\text { Interfascial ONB method } \\
(n=2)\end{array}$ & - & $2(4.9)$ & - & - & $2(1.2)$ & \\
\hline Total & $46(27.1)$ & $34(20.0)$ & $48(28.2)$ & $42(24.7)$ & $170(100.0)$ & \\
\hline
\end{tabular}


relaxants $(51.8 \%, n=88)$, and regional anesthesia and ONB $(36.5 \%, n=62)$, respectively. Twelve (7.1\%) participants reported that decreasing the bladder pressure and using a low current would be sufficient in TURBT for preventing adductor spasm.

A 5-point Likert scale was used for the opinions of the urologists on ONB; the results are presented in Table IV.

\section{Discussion}

Bladder tumors in the male population are the $7^{\text {th }}$ most frequently detected tumor type. First, transurethral resection of the bladder (TURB) is performed for the diagnosis, staging, and treatment $[13,14]$. Complications such as bladder perforation and vessel-nerve injuries may develop during TURB. The location of the tumor, the tumor size, surgical experience, and adductor muscle spasm, which develops due to stimulation of the obturator nerve, may be counted as factors that have a role in the development of complications [4, 15].

Adequate resection must be performed for staging and for adequate treatment [16]. The complication rate increases during TURB due to the development of inappropriate surgical conditions not associated with the adductor muscle contraction, which results in inadequate resection and inadequate treatment [17]. The ONB, which is performed for prevention of adductor muscle contraction, is an effective method for enabling an appropriate environment for surgery [18]. The ONB has been shown to be a basic skill for urologists in addition to the other methods during TURBT [19]. In accordance with the responses of the participant urologists, ONB was frequently performed by urologists, and less frequently by anesthesiol- ogists. In addition, the majority of the urologists suggested that ONB would enable an adequate resection, and might decrease the recurrence rate. However, in our study, approximately half of the urologists did not prefer ONB.

The obturator nerve may be blocked in the obturator foramen, or between the $m$. adductor longus, brevis, and magnus muscles after coming out of the lumbar plexus at the level of $L 2-L 4$ for the prevention of adductor spasms. Paravesical, classic intravesical, inguinal, and interfascial methods have been used for the block [8, 20]. We found that both urologists and anesthesiologists frequently preferred the classic method for ONB. In the literature, urologists frequently use transurethral ONB using the blinding method [11, 12] and anesthesiologists prefer to use peripheral nerve stimulator and/or ultrasonography to avoid local anesthesia toxicity and vessel injuries [9]. In our study, we found that the number of applications of ONB methods by anesthesiologists was 22. The anesthesiologists prefer the blinding method for ten blocks; the remainder use a peripheral nerve stimulator and/or ultrasonography. On the other hand, other factors should be questioned in order to determine the reason why urologists prefer to use the blinding method ( $n=32)$ for ONB application in our study.

General anesthesia together with muscle relaxants may be performed for the prevention of adductor muscle contraction, and a safe resection area may be created [21]. However, general anesthesia may have high risks due to many accompanying diseases in the age group of the affected patient population. Therefore, TURBT has frequently been performed under regional anesthesia [17, 22]. Some of the participating urologists suggested that adequate resection may be performed us-

Table IV. Opinions of the urologists about obturator nerve block

\begin{tabular}{|c|c|c|c|c|c|c|c|}
\hline \multirow[t]{3}{*}{ Variable } & $\begin{array}{l}\text { Strongly } \\
\text { agree }\end{array}$ & I Agree & $\begin{array}{l}\text { I have no } \\
\text { idea }\end{array}$ & $\begin{array}{l}\text { I do not } \\
\text { agree }\end{array}$ & $\begin{array}{l}\text { I strongly } \\
\text { disagree }\end{array}$ & \multirow[t]{3}{*}{ Mean } & \multirow[t]{3}{*}{ Median } \\
\hline & 1 & 2 & 3 & 4 & 5 & & \\
\hline & $n(\%)$ & $n(\%)$ & $n(\%)$ & $n(\%)$ & $n(\%)$ & & \\
\hline $\begin{array}{l}\text { Enables adequate resection thus } \\
\text { decreasing the recurrence rate }\end{array}$ & $48(28.2)$ & $56(32.9)$ & $28(16.5)$ & $10(5.9)$ & $4(2.4)$ & 2.1 & 2 \\
\hline The procedure takes a long time & $18(10.6)$ & $42(24.7)$ & $46(27.1)$ & $20(11.8)$ & $6(3.5)$ & 2.7 & 3 \\
\hline The success rate is low & $6(3.5)$ & $34(20.0)$ & $52(30.6)$ & $30(17.6)$ & $10(5.9)$ & 3.0 & 3 \\
\hline It is difficult to perform & $8(4.7)$ & $56(32.9)$ & $44(25.9)$ & $24(14.1)$ & $4(2.4)$ & 2.7 & 3 \\
\hline $\begin{array}{l}\text { Complications may frequently be } \\
\text { detected }\end{array}$ & $4(2.4)$ & $26(15.3)$ & $60(35.3)$ & $30(17.6)$ & $10(5.9)$ & 3.1 & 3 \\
\hline $\begin{array}{l}\text { Requires equipment (stimulator } \\
\text { or USG) }\end{array}$ & $18(10.6)$ & $54(31.8)$ & $50(29.4)$ & $8(4.7)$ & $6(3.5)$ & 2.5 & 2 \\
\hline $\begin{array}{l}\text { It is not preferred by } \\
\text { anesthesiologists }\end{array}$ & $28(16.5)$ & $58(34.1)$ & $38(22.4)$ & $12(7.1)$ & $8(4.7)$ & 2.4 & 2 \\
\hline
\end{tabular}


ing low electrical current by enabling low pressure in the bladder with modern resectoscopes under regional anesthesia in TURBT procedures. However, the majority of urologists preferred the use of general anesthesia and muscle relaxants. Regional anesthesia is frequently performed in high-risk group patients. Considering the possible additional risk of general anesthesia, the preference of general anesthesia and muscle relaxants by both the urologists and anesthesiologists must be questioned. Additional studies must be conducted to ascertain why anesthesiologists mainly did nothing against adductor muscle contraction, or used general anesthesia. Is there not good communication between the anesthesiologists and urologists, or is according to both teams general anesthesia more effective?

Other methods used by urologists in TURBT for the prevention of adductor muscle contraction are injections to the lateral bladder wall, bipolar cautery techniques, and the change of solutions [14]. In our study, the urologists mainly used different methods independently of the anesthesiologists. Lowering the cautery current, immediate step on and step off of the foot switch maneuver, decreasing the bladder volume, and local injection to the bladder wall were used alone or together with other methods. More than half of the urologists used isotonic saline as the irrigation fluid, and less frequently used mannitol, and glycine. Zhao et al. found in their metaanalysis that bipolar cautery was more advantageous during TURBT [23]. Half of the urologists used bipolar cautery; however, approximately $40 \%$ used monopolar cautery in our study. We could not detect the reason why the urologists used different irrigation fluids and cautery because these were not questioned in the study.

The use of different drug concentrations, and different volumes using different methods, was observed in studies that investigated ONB methods [10-12]. Similar to these studies, both the urologists and anesthesiologists used local anesthesia drugs in different concentrations and doses in our study. We anticipated that the difference in the selection of the drugs would change in accordance with the centers where the individuals were educated and with their personal experiences.

One of the limitations of our study is that we did not investigate the education and competency of both the urologists and anesthesiologists in ONB practices. Another limitation is that we did not ask the urologists whether they requested ONB or general anesthesia from the anesthesiologists. Therefore, we could not completely identify the causes of the lower preference of ONB. We have planned studies for anesthesiologists on this topic with the inclusion of similar questions.
We suggest that anesthesiologists and urologists working towards the same goal must have more communication to enable optimal surgical conditions for TURBT. We believe that both anesthesiologists and urologists may improve their skills in ONB with reciprocal interaction, and thus would prefer and perform more ONB.

In conclusion, urologists use different methods for the prevention of adductor muscle contraction in TURBT in accordance with their personal skills. ONB is used less often and is less preferred than general anesthesia and muscle relaxants by both urologists and anesthesiologists.

\section{Acknowledgments}

We would like to thank the Society of Urological Surgery in Turkey for their help in sending the forms to the urologists.

\section{Conflict of interest}

The authors declare no conflict of interest.

\section{References}

1. Sert IU. Obturatorius blokaji. In: Sert IU. TURP Trans Uretral Prostat ve Mesane Tümörü Rezeksiyonu. $1^{\text {nd }}$ ed. Istanbul: Nobel Tıp Kitabevi 2017; 64-9.

2. Zengin K, Başay S. TUR'a bağı ı mesane perforasyonu: tedavi ve izlem. Üroonkoloji Bülteni 2011; 1: 38-40.

3. Ong EL, Chan ST. Transurethral surgery and the adductor spasm. Ann Acad Med Singapore 2000; 29: 259-62.

4. Kati B, Izgi M. A nightmare during endoscopic bladder tumor resection: obturator reflex. J Turgut Ozal Med Cent 2017; 24: 371-4.

5. Ozer K, Horsanali MO, Gorgel SN, Ozbek E. Bladder injury secondary to obturator reflex is more common with plasmakinetic transurethral resection than monopolar transurethral resection of bladder cancer. Centr Eur J Urol 2015; 68: 284-8.

6. Miki M, Shiozawa H, Matsumoto T, Aizawa T. Transurethral resection in saline (TURis): a newly developed TUR system preventing obturator nerve reflex. Nihon Hinyokika Gakkai Zasshi 2003; 94: 671-7.

7. Jo SY, Chang JC, Bae HG, Oh JS, Heo J, Hwang JC. A Morphometric study of the obturator nerve around the obturator foramen. J Korean Neurosurg Soc 2016; 59: 282-6.

8. Moningi S, Durga P, Ramachandran G, Murthy PV, Chilumala RR. Comparison of inguinal versus classic approach for obturator nerve block in patients undergoing transurethral resection of bladder tumors under spinal anesthesia. J Anaesthesiol Clin Pharmacol 2014; 30: 41-5.

9. Shah NF, Sofi KP, Nengroo SH. Obturator nerve block in transurethral resection of bladder tumor: a comparison of ultrasound-guided technique versus ultrasound with nerve stimulation technique. Anesth Essays Res 2017; 11: 411-5.

10. Pladzyk K, Jureczko L, Lazowski T. Over 500 obturator nerve blocks in the lithotomy position during transurethral resection of bladder tumor. Cent Eur J Urol 2012; 65: 67-70.

11. Khorrami M, Hadi M, Javid A, et al. A comparison between blind and nerve stimulation guided obturator 
nerve block in transurethral resection of bladder tumor. J Endourol 2012; 26: 1319-22.

12. Tatlisen A, Sofikerim M. Obturator nerve block and transurethral surgery for bladder cancer. Minerva Urol Nefrol 2007; 59: 137-41.

13. Babjuk M, Bohle A, Burger M, et al. EAU guidelines on non-muscle-invasive urothelial carcinoma of the bladder: update 2016. Eur Urol 2017; 71: 447-61.

14. Richards KA, Smith ND, Steinberg GD. The importance of transurethral resection of bladder tumor in the man agement of nonmuscle invasive bladder cancer: a systematic review of novel technologies. J Urol 2014; 191: 1655-64.

15. Nieder AM, Meinbach DS, Kim SS, Soloway MS. Transurethral bladder tumor resection: intraoperative and postoperative complications in a residency setting. J Urol 2005; 174: 2307-9.

16. Jurewicz M, Soloway MS. Approaching the optimal transurethral resection of a bladder tumor. Turk J Urol 2014; 40: 73-7.

17. Nieder AM, Manoharan M. The role of the surgeon and transurethral resection in the treatment of superficial bladder cancer. Sci World J 2006; 6: 2626-31.

18. Erbay G, Akyol F, Karabakan M, Celebi B, Keskin E, Hirik $\mathrm{E}$. Effect of obturator nerve block during transurethral resection of lateral bladder wall tumors on the presence of detrusor muscle in tumor specimens and recurrence of the disease. Kaohsiung J Med Sci 2017; 33: 86-90.

19. Furuse H, Ozono S. Transurethral resection of the bladder tumour (TURBT) for non-muscle invasive bladder cancer: basic skills. Int J Urol 2010; 17: 698-9.

20. Hizli F, Argun G, Guney I, et al. Obturator nerve block transurethral surgery for bladder cancer: comparison of inguinal and intravesical approaches: prospective randomized trial. Ir J Med Sci 2016; 185: 555-60.

21. Cesur M, Erdem AF, Alici HA, Yapanoglu T, Yuksek MS, Aksoy $Y$. The role of succinylcholine in the prevention of the obturator nerve reflex during transurethral resection of bladder tumors. Saudi Med J 2008; 29: 668-71.

22. Choi WJ, Baek S, Joo EY, et al. Comparison of the effect of spinal anesthesia and general anesthesia on 5-year tumor recurrence rates after transurethral resection of bladder tumors. Oncotarget 2017; 8: 87667-74.

23. Zhao C, Tang K, Yang H, Xia D, Chen Z. Bipolar versus monopolar transurethral resection of nonmuscle-invasive bladder cancer: a meta-analysis. J Endourol 2016; 30: 5-12. 